\title{
A Conversation with Paul Glimcher
}

\author{
INTERVIEWER: REBECCA LESHAN \\ Director, Banbury Center, Cold Spring Harbor Laboratory
}

\begin{abstract}
Paul Glimcher is a Professor of Neural Science, Economics, and Psychology at New York University (NYU) and Director of NYU's Institute for the Interdisciplinary Study of Decision Making.
\end{abstract}

Rebecca Leshan: Could you start us off by just giving us a little bit of background about your research?

Dr. Glimcher: My lab's really focused on understanding the core underlying biological basis of how we make decisions. That's an area that we knew very little about 20,30 years ago. We knew a lot about Pavlovian conditioning but really didn't think about how people make choices and what the neural architecture for that looks like. Over the course of the last 25 years, as a community we've made tremendous strides in making fundamental insights into that. I think at this point we can say that we understand the basic neural architecture for making decisions. We understand how parts of the frontal cortex generate values, store them, how we learn what we like and what we don't like, and then how those values are passed to areas of the frontal and parietal cortex for decision-making, for weighing options in a very formal, mathematical sense. It's been a really exciting field to be in for the last 25 years, because it's really a field that was born pretty much 25,30 years ago. At this point we really have laid the groundwork for understanding how to change policy, how to understand things like drug addiction, how to understand decisionmaking.

Rebecca Leshan: I hear a lot in this field the term "neuroeconomics." You wouldn't necessarily always put neuroscience and economics together, and you've done just that. Can you tell me about branching that divide, and how difficult it was for you as a trained neuroscientist to say, "Hey economists, here I am?"

Dr. Glimcher: Well, it is a challenge. It is, of course, now a field: neuroeconomics. It really grew out of the intuition by a small group of the neuroscientists and a small group of the economists in the 1990s and early 2000s that the two fields had something to offer each other. Economists have been thinking for about 300 years about how we make decisions. What do you consider when you weigh an option? How ought the option to be represented over the course of the decision-making process? Neuroscientists have thought a tremendous amount over that same period about the neural pathways that connect sensation and action. It seemed kind of obvious in, let's say 2000, maybe 1995-1998, that those two fields should merge, but it was hard, because the fields spoke completely different languages.

I was trained as a physiologist at the University of Pennsylvania, and we didn't think about representational theorems. We didn't think about: How does the nature of the representation of subjective or idiosyncratic value condition our actions? It was a long, slow process to learn to speak economics. For me, personally, the odyssey was one that went first from neuroscience to the psychology of judgment and decision-making, which was a smaller step. I worked my way as a young assistant professor through a lot of the psychology of judgment and decision-making and a lot of the graduate curricula at NYU.

Then, what actually happened next for me was, I started to hang out with foraging theorists. These are a bunch of mostly crusty old men in the West who knew a fair bit of math and were interested in how does a moose decide whether to eat-I guess freshwater-seaweed or decide to eat grass. There are optimal solutions to these problems that can be written down. All of the original group of foraging theorists saw themselves as studying decision-making by animals in the wild. I thought, "Well, this is the next natural step. I study decision-making in both humans and animals, so maybe what I study is foraging theory."

A bunch of the older foraging theorists, particularly Ric Charnov, who's really the grandfather of all foraging theory, took me under their wings. At some point Ric Charnov took me aside, and he said in a sort of brilliant, crusty old field ecologist way, "Paul, you have to become an economist, because what you're doing is Economics-Lite. If you want to understand human decision-making, you got to fully incorporate what the economists have learned."

So, I famously went across the street to the Econ Department at NYU to the Director of Undergraduate Studies, who I knew, and said, "I want to become an economist." He said, "I've one piece of advice," and I said, "Oh great, great." He said, "Go back to the elevator, go downstairs, go across the street, and never come here again."

I said, "I'm really serious. I really want to be an economist."

(C) 2018 Glimcher. This article is distributed under the terms of the Creative Commons Attribution-NonCommercial License, which permits reuse and redistribution, except for commercial purposes, provided that the original author and source are credited. 
Rebecca Leshan: That was the test...

Dr. Glimcher: No, it wasn't.

Rebecca Leshan: ... to refuse you several times?

Dr. Glimcher: No, it wasn't. I mean, he said, 'I'm really serious. The last thing anyone needs is a neuroscientist who can speak economics." They really shut the door initially on me. Then I learned that there were a group of economists interested in understanding neurobiological restrictions of human decision-making. The person who played the largest role was a professor at Caltech by the name of Colin Camerer. I had just written my first book; Colin had just written his first book. I wrote him a letter, and he said, "So, let's start talking." Colin gave me enough background that I could go back to the department a year later and say, "No, I'm really serious." I'm now a Professor of Economics at NYU.

But it was a very slow process, really learning how to speak like an economist. Economists are extremely sensitive to beauty and poetry. A good economic theory is a beautiful economic theory. Poetry in formalisms is really important. I think the first 5 or 10 years of neuroeconomics were characterized by people stumbling, because they just didn't understand the aesthetics of economists. That's so important, and it's hard to appreciate how important the blinders we put around ourselves are and the aesthetics that we operate under. It's true of neuroscience, but I'm used to it. To learn to see neuroscience from the point of view of an economist was hard, but then incredibly validating.

Rebecca Leshan: There are a number of people in neuroscience who either have come from a different field or have branched out into other fields, but it's typically something a little bit closer, like maybe physics.

Dr. Glimcher: I think physics is in some ways more like economics than like neuroscience. I mean, it is a hard reach. Economists don't, as a group, believe in ground truth, nor should they. They build models that predict the behavior and explain the behavior of humans. If you say, "Well, is that how it's really done?" you get a question like, "Why is that even a question? Why are you asking that? Why is it relevant?" When a young neuroscientist comes to an economist and says, "That's impossible. I can prove it's not computable that way," an economist would say, "Who cares? Why is that even relevant?" At my institute at NYU, we have this really strict rule, which is, you can't criticize a field until you can defend it. I think that's really the key to real interdisciplinary work.

I have young people come to my office all the time who say, "I want to do interdisciplinary work. That's why I'm here." I say, "That's great." I say, "How were you trained?" They say, "Oh, I'm a biologist." Then what they'll explain to you is their notion of interdisciplinary work is explaining to psychologists, or economists, or sociologists, that they're wrong and that the background this kid has is right. You have to get to this place where you say to them, "It's not about telling the other person they're wrong." The best thing you can do is say: "You're not allowed to attack the economics until you can defend it."
Lots of times people will say to me "The problem with economists is that they hold this view, this peculiar view 'X,' which is dumb," and you have to say, "Really? You get that these people are smarter than us, right?" So, it's not because they're dumb. There's a reason.

Rebecca Leshan: It's understanding. I think data feels like it's been such a revolution to a lot of different fields in science, and it's something that I think has been used by economists. I wonder if data is something that can bring together disparate fields. For example, the Human Project, which you are involved with, that's something where you're getting all of this information, and all of this data can be used by so many different people.

Dr. Glimcher: It goes both ways. There's an old saying in economics, which is that "No good theory was ever killed by data." This speaks to the fact that, for an economist, beauty and explanatory power are really important and sometimes trump data. That's a hard feature, and it's not true of all areas of economics, but it is sometimes true. But large-scale data is something that economists grew up with. A typical international economist might have data about the growth of 300 countries in a time series that goes back 300 years. As neuroscientists, we've only just begun to start to explore large data sets, so I think there is a gap there.

Economists have beautiful tools for doing stuff like that. As a first-year student you take econometrics, which is a really murderously difficult data analytics course. We don't really have stuff like that in neuroscience. We're just starting to understand large data sets and how to think about them. Sometimes we reinvent the wheel when we don't need to. So, I agree that the toolkits of the economists are really much better tools for large-scale data. For me, a project like the Human Project is an effort to unite those data sets, to build single data sets that span all the way from genetics to cash expenditures in the face of budget limitations.

Rebecca Leshan: I want to switch gears back into the brain. A lot of work in decision-making is looking at the level of the cortex. Do you think about those "lower brain regions?" When you talked about foraging, I was thinking about nutrient value. How do you unite those two?

Dr. Glimcher: I think it's a terrible mistake that we overfocus on cortex. There are lots of historical reasons for that. There are lots of technical reasons for that. The basal ganglia have been a serious focus for people studying decision-making - certainly for the last 20 years, since the late ' $80 \mathrm{~s}$ - so understanding the role of dopamine in decision-making, understanding the role of the dorsal and ventral striatum, the caudate and putamen in monkeys... My lab - lots of labs — have done recording there, fMRI [functional magnetic resonance imaging] work there, lesion work there. I think decision-making is really a deeply interlocked corticobasal ganglia function. There's no doubt about that at this point. Anybody that says otherwise is itching for a fight, in my opinion.

Now, understanding how metabolic need and how satiety works... I actually grew up in labs where animals were 
self-stimulating. They were being sated, and it was changing the rates at which they self-stimulated. All of those hypothalamic circuits for valuing the consummatory act for different kinds of what, as an economist, I would call "goods," that's an area where neuroeconomics has not made as much headway as maybe it should have. We've learned so much in the last 5 to 10 years about the ghrelin/ leptin cycle. We know a lot more about how metabolic demand and the hypothalamus work together, but you don't see really clean integration of those models into decision-making. You see it in a sort of cursory way.

I'll give an example from my own work: We've studied metabolic demand, risk attitude, and decision-making with regard to water. To do that, we've had monkeys, and we've been real-time sampling their blood osmolality and looking at how changes in blood osmolality change the decision-making and risk attitude. But to take that to the next step and to talk about osmosensors in the neck and osmoregulation in the hypothalamus, that's a piece that hasn't happened yet. You still see the traditional kind of physiological psychology approach mostly dominating the hypothalamus. We see these points where the two fields almost touch. I would love to see more work that connected the traditional physiological psychologists like Don Pfaff with... I mean, there's interest, and people talk about it, but I don't think they really knit together yet.

Rebecca Leshan: A lot of optogenetic studies are in rodents, and a lot of the more traditional behavioral studies, as you want to relate to humans, are in nonhuman primates. Do you see that as a disconnect? Do those two fields need to be joined as well?

Dr. Glimcher: There's a group of young rodent physiologists who are asking the question, "How do we use traditional economic models to understand rodent decision-making, both rats and mice?" So, you see people as far afield as Jeff Erlich at NYU Shanghai, Carlos Brody at Princeton, and here [Cold Spring Harbor Laboratory]: Adam Kepecs, Tony Zador, Zach Mainen, who came from here. I see this whole group of people who are asking the question, "How do we use hard-core decision-making tools to understand decision-making with rodents as a model for understanding primates like us and monkeys." So, I think that's happening, but it's happening in a subgroup of the rodent field.

There've been efforts to use optogenetics for understanding monkey decision-making, but they have not been successful, and it's because we don't have Cre, and CRISPR is still in its infancy in primates. When you think about technologies like AAV [adeno-associated virus] transfection, there have been successes, but they've been very hard to get to work in primates, and many a lab has burnt many an hour. There's just a handful of great landmark papers.

Rebecca Leshan: Is there something that you are really excited about? Maybe something that surprised you, or somewhere that you're really excited to take the field of decision-making into, whether it's a disease state, a disordered brain?

Dr. Glimcher: I do think, now that we understand the decision-making architecture as well as we do, we really have to use that to address the major policy issues that we face with regard to mental health and metabolic health. The two things that are pressing national epidemics are the opioid epidemic and the obesity epidemic, which lean both on my interest in dopamine and in the hypothalamus. More and more, I find my lab's work focusing on using the tools, neurobiological and behavioral, that we've developed to understand: When is a person at risk for addiction? When is a person at risk for relapse who has been treated for addiction? What are the brain changes? How do changes in things like striosomes and matrix over the course of disease states manifest as increased or decreased risks?

We have developed a robust treatment architecture for obesity and drug addiction but honestly, they're not terribly effective. People who are obese stay obese, and people who are addicted to drugs are, to some degree, addicts their whole lives. It's striking that we have failed as neurobiologists to cure those diseases. At best, we treat them. One of the probably many missing pieces is an understanding of decision-making. As we get to a place where we can now look at how you choose to consume drugs or how the signals from your hypothalamus cause you to choose to eat, how we understand those circuits hopefully will be the golden key that unlocks an actual cure and not just a treatment. For me, that's a really exciting area.

I see this in computational psychiatry all the time. The birth of computational psychiatry in the last few years is, I think, an act of exciting, optimistic... Can we bring the kinds of tools that my generation developed when we were younger to policy problems today? The idea that the constructs of psychiatry will be anchored to the computational neuroscience of behavior, that's obviously the future of psychiatry. Hopefully, it will be the future of effective treatments for these disorders. 


\section{$\$_{\text {CSH\& }}^{\infty}$ Cold Spring Harbor Symposia SYMPOSIA}

\section{A Conversation with Paul Glimcher}

Cold Spring Harb Symp Quant Biol 2018 83: 249-251 originally published online February 11, 2019

Access the most recent version at doi:10.1101/sqb.2018.83.037317
Creative This article is distributed under the terms of the
Commons http://creativecommons.org/licenses/by-nc/4.0/, which permits reuse and
License redistribution, except for commercial purposes, provided that the original author and source are credited.

Email Alerting Receive free email alerts when new articles cite this article - sign up in Service the box at the top right corner of the article or click here. 